\title{
The use of gonadotropin-releasing hormone antagonist post-ovulation trigger in ovarian hyperstimulation syndrome
}

\author{
Neil Chappell, William E. Gibbons
}

Division of Reproductive Endocrinology and Infertility, Department of Obstetrics and Gynecology, Baylor College of Medicine, Houston, TX, USA

The purpose of this paper is to assimilate all data pertaining to the use of gonadotropin-releasing hormone (GnRH) antagonists in in vitro fertilization cycles after ovulation trigger to reduce the symptoms of ovarian hyperstimulation syndrome (OHSS). A systematic review of the literature was performed to identify all studies performed on the use of a GnRH antagonist in IVF cycle post-ovulation trigger with patients at high risk for OHSS. Ten studies were identified and reviewed. Descriptions of the studies and their individual results are presented in the following manuscript. Due to significant heterogeneity among the studies, it was not possible to perform a group analysis. The use of $\mathrm{GnRH}$ antagonists post-ovulation trigger for treatment of OHSS has been considered for almost 20 years, though research into its use is sparse. Definitive conclusions and recommendations cannot be made at this time, though preliminary data from these trials demonstrate the potential for $\mathrm{GnRH}$ antagonists to play a role in the treatment of OHSS in certain patient populations.

Keywords: Antagonist; Gonadotropin-releasing hormone; Ovarian hyperstimulation; Ovarian hyperstimulation syndrome

\section{Introduction}

In assisted reproductive technology, ovarian hyperstimulation syndrome (OHSS) carries a $3 \%$ to $5 \%$ incidence and remains a serious complication. Risk factors include polycystic ovary syndrome, young age, low body weight, increasing gonadotropin doses, high estradiol or anti-Müllerian hormone levels, and prior episode of OHSS [1,2]. Given its iatrogenic nature, any steps that can be taken to decrease the risk and morbidity are warranted. One contributor to the mechanism of OHSS is human chorionic gonadotropin (hCG) exposure, either via ovulation trigger or by pregnancy resulting from embryo

Received: Mar 11, 2017 · Revised: May 17, 2017· Accepted: May 17, 2017 Corresponding author: Neil Chappell

Division of Reproductive Endocrinology and Infertility, Department of Obstetrics and Gynecology, Baylor College of Medicine, 6651 Main St, 10th Floor, Houston, TX 77030, USA

Tel:+1-318-366-1146 Fax:+1-832-825-9350 E-mail: Neil.Chappell@bcm.edu

This is an Open Access article distributed under the terms of the Creative Commons Attribution Non-Commercial License (http://creativecommons.org/licenses/by-nc/4.0/) which permits unrestricted non-commercial use, distribution, and reproduction in any medium, provided the original work is properly cited. transfer. The innate ability of hCG to mimic the luteotropic effects of luteinizing hormone (LH) activity with a much longer half-life permits prolonged ovarian stimulation beyond that of normal physiology [3]. Additionally, ovarian production of vascular endothelial growth factor (VEGF) increases vascular capillary permeability, a wellknown hallmark of OHSS [1,2]. To date, focus has been placed on reducing the rate of $\mathrm{OHSS}$, particularly prior to triggering ovulation and subsequent oocyte retrieval, with emphasis on the concept of minimizing the stimulatory effects on the ovary. Some methods include the use of gonadotropin-releasing hormone (GnRH) antagonist protocol, decreasing or abstaining from gonadotropin injections ("coasting"), the use of GnRH agonist triggers, metformin, or cancelling a cycle altogether [4]. Other studies have shown benefits in interventions after the ovulation trigger, via cancelling fresh embryo transfers to avoid pregnancy, administering dopamine agonists to block VEGF activity, or other medications such as letrozole, mifepristone, or infusion of macromolecules, though the latter intervention has come with reports of increased morbidity [5-8]. Interestingly, one recent study to date has investigated the use of kisspeptin as an ovulation 
trigger to decrease the risk of OHSS [9]. While these advances have shown some measure of benefit, OHSS remains a clinically meaningful entity, and continued research into mitigating this outcome is warranted [10]. To this end, there are a small handful of studies have investigated the use of $\mathrm{GnRH}$ antagonists after ovulation trigger and oocyte retrieval to reduce the effects of OHSS, and it is these data on which this paper intends to focus.

GnRH antagonists have been in use for approximately 20 years in the field of assisted reproductive technology. Firstly, use of an antagonist in an in vitro fertilization (IVF) protocol to suppress premature ovulation (known as the antagonist protocol) has been compared to the use of a GnRH agonist ("long" or "long luteal" protocol) and been shown to decrease the amount of total gonadotropin dose, days of stimulation, and risk of hyperstimulation without adverse effects on success rates [11-13]. Further, the immediate suppression of the hypothalamic-pituitary axis with an antagonist provides the option of switching from an agonist to an antagonist in cycles where patients are shown to have robust responses to the gonadotropins and thus be at higher risk for OHSS. Second, an antagonist allows for use of a $\mathrm{GnRH}$ agonist trigger in place of $\mathrm{hCG}$, and its associated longer halflife, for ovulation trigger prior to egg retrieval, which further lowers the risk for OHSS [13]. However, it should be noted that some data suggest the use of a GnRH agonist trigger alone has lower pregnancy rates in fresh transfer cycles than compared to HCG trigger $[13,14]$. Regardless, given the evidence showing risk reduction in OHSS with the use of the antagonist before the trigger, the use of the antagonist has been suggested post-trigger in high risk patients in an effort to attenuate the effects of OHSS. The purpose of this paper is to serve as a systematic review of this literature to date.

\section{Methods}

In an effort to identify studies investigating the clinical use of $\mathrm{GnRH}$ antagonists after the ovulation trigger to treat OHSS, a systematic literature search was conducted. Studies were identified by searching MEDLINE (January 1990-July 2016). Results were limited to peer-reviewed and English language studies only. The search strategy included the following terms: "gonadotropin releasing hormone," "GnRH," "antagonist," "ovarian hyperstimulation syndrome," and "OHSS." Further studies were accumulated after performing review of works cited in reviewed publications. All titles and abstracts were reviewed by one author (NC). Full text review was performed by the same, as well as validation and verification by WEG. Initially, 394 studies were identified in the primary search, of which 385 were excluded due to reasons enumerated in Table 1. The remaining nine studies were reviewed, with one additional study identified by review of the citations of previously listed articles for a total of 10 clinical studies.
Table 1. Exclusion criteria for studies

Exclusion criteria

- Antagonist only given prior to ovulation trigger

- Not an article on ovarian hyperstimulation syndrome

- No use of gonadotropin-releasing hormone antagonist

- Animal study

Details of the studies are represented in Table 2. As this study was a review of previously published literature, no institutional review board approval was required.

\section{Results}

The first study that investigated the use of a GnRH antagonist in treating OHSS was a case report from the Netherlands by de Jong et al. [15] in 1998. The case describes a 33-year-old patient undergoing an IVF cycle with the antagonist protocol using $0.125 \mathrm{mg}$ of ganirelix that subsequently developed significant follicular growth and a high estradiol level. The cycle was cancelled, no trigger was given, and the patient instead received an increased dose of the ganirelix of $2 \mathrm{mg}$ per day for 3 days which resulted in a rapid decline in the estradiol levels and improvement in the patient's symptoms.

Lainas in Greece followed this study with several reports. In these papers, he describes patients diagnosed with moderate to severe OHSS on post-retrieval day 3 to 5 , using the criteria of ovarian volume $>10 \mathrm{~cm}^{3}$, marked ascites, hematocrit $>45 \%$, white blood cell count $>15,000 / \mathrm{mm}^{3}$, or serum creatinine $>1.0 \mathrm{mg} / \mathrm{dL}$. Of note, in all of the papers by Lainas subsequently discussed, the patients were triggered with 5,000 IU of HCG. The first of these case reports, published in 2007, describes three patients with polycystic ovary syndrome that were subsequently treated with ganirelix $0.25 \mathrm{mg}$ daily, starting on post-retrieval day 3 for the next 7 days. These patients were described to have had a quick resolution of symptoms with none requiring hospitalization [16]. In 2009, a similarly designed study was performed, again with three patients treated with ganirelix $0.25 \mathrm{mg}$ daily for 1 week, though this was started on all three patients on post-retrieval day 6 . The study resulted in similar findings of resolution of symptoms by post trigger day 11, defined by normalization of the measured parameters mentioned above (ovarian volume, hematocrit, white blood cell count, and serum creatinine) and no hospitalizations [17].

Three other case reports by different authors were identified for this review. From the United States, Rollene et al. [18] published in 2009 a series of four patients diagnosed with OHSS on the day of retrieval that were treated with cabergoline $0.5 \mathrm{mg}$ for 7 days along with ganirelix $0.25 \mathrm{mg}$ daily for two doses initiated 1 to 2 days postretrieval. Patient symptoms resolved within 5 days with no reported 
Table 2. Summary of studies identified

\begin{tabular}{|c|c|c|c|c|c|c|}
\hline Study & Country & Design & $\mathrm{n}^{\mathrm{a})}$ & IVF protocol'b) & Treatment & $\begin{array}{l}\text { Summary of outcomes } \\
\text { reported }\end{array}$ \\
\hline De Jong et al. (1998) [15] & The Netherlands & Case report & 1 & Antagonist, no trigger & $\begin{array}{l}\text { Ganirelix } 2 \text { mg daily, IVF cycle can- } \\
\text { celled }\end{array}$ & $\begin{array}{l}\text { Decrease in serum estradiol, } \\
\text { ovarian volume, and ascites }\end{array}$ \\
\hline Lainas et al. (2007) [16] & Greece & Case report & 3 & - & $\begin{array}{l}\text { Ganirelix } 0.25 \mathrm{mg} \text { daily post-re- } \\
\text { trieval day 3-9 }\end{array}$ & $\begin{array}{l}\text { Resolution of symptoms and } \\
\text { no hospitalizations }\end{array}$ \\
\hline $\begin{array}{l}\text { Bonilla-Musoles et al. } \\
\text { (2009) [19] }\end{array}$ & Spain & Case report & 6 & Unavailable & Cetrotide $3 \mathrm{mg}$ for $1-2$ doses & $\begin{array}{l}\text { Decreased estradiol levels and } \\
\text { improvement of ascites }\end{array}$ \\
\hline Lainas et al. (2009) [21] & Greece & Case report & 3 & Antagonist & $\begin{array}{l}\text { Ganirelix } 0.25 \mathrm{mg} \text { daily post-re- } \\
\text { trieval days } 6-8 \text { with embryo } \\
\text { transfer on day } 6\end{array}$ & $\begin{array}{l}2 \text { Live births and } 1 \text { biochemical } \\
\text { pregnancy reported }\end{array}$ \\
\hline Rollene et al. (2009) [18] & The United States & Case report & 4 & Mixed & $\begin{array}{l}\text { Ganirelix } 0.25 \mathrm{mg} \text { daily for } 2 \text { days } \\
\text { post-retrieval along with cab- } \\
\text { ergoline } 0.5 \mathrm{mg} \text { daily for } 7 \text { days }\end{array}$ & $\begin{array}{l}\text { Rapid improvement in weight } \\
\text { gain and symptoms, no hos- } \\
\text { pitalizations }\end{array}$ \\
\hline Lainas et al. (2012) [22] & Greece & Prospective cohort & $353(40)$ & $\begin{array}{l}\text { Antagonist or long luteal, } \\
\text { hCG or GnRH agonist trigger }\end{array}$ & $\begin{array}{l}40 \text { High-risk patients received } \\
\text { ganirelix } 0.25 \mathrm{mg} \text { daily post-re- } \\
\text { trieval days } 5-8\end{array}$ & $\begin{array}{l}\text { Rapid decline in hematocrit, } \\
\text { ovarian volume, estradiol, and } \\
\text { progesterone over } 2 \text { days, and } \\
\text { no hospitalizations }\end{array}$ \\
\hline Hosseini et al. (2012) [20] & Iran & $\begin{array}{l}\text { Prospective } \\
\text { matched cohort }\end{array}$ & $27(13)$ & - & $\begin{array}{l}13 \text { Patients with early OHSS treat- } \\
\text { ed with Cetrotide } 0.25 \text { mg daily } \\
\text { for } 2 \text { doses post-retrieval com- } \\
\text { pared to } 14 \text { prior patients un- } \\
\text { treated }\end{array}$ & $\begin{array}{l}\text { Lower rates of OHSS, hospital- } \\
\text { ization, paracentesis, and acute } \\
\text { care in the Cetrotide group }\end{array}$ \\
\hline Lainas et al. (2013) [23] & Greece & Prospective cohort & $192(22)$ & $\begin{array}{l}\text { Antagonist or long luteal, } \\
\text { hCG or GnRH agonist trigger }\end{array}$ & $\begin{array}{l}22 \text { High-risk patients received } \\
\text { ganirelix } 0.25 \text { mg daily post-re- } \\
\text { trieval days } 5-7 \text { with embryo } \\
\text { transfer (experimental group); } \\
172 \text { patients received embryo } \\
\text { transfer only (control group) }\end{array}$ & $\begin{array}{l}\text { Obstetric and neonatal outco- } \\
\text { mes similar between groups }\end{array}$ \\
\hline Lainas et al. (2014) [24] & Greece & Prospective cohort & 12 & $\begin{array}{l}\text { Antagonist or luteal, } \\
\text { hCG or GnRH agonist trigger }\end{array}$ & $\begin{array}{l}\text { Ganirelix } 0.25 \text { mg daily } \\
\text { post-retrieval days 5-8 }\end{array}$ & $\begin{array}{l}\text { Significant decline of VEGF lev- } \\
\text { els on day } 7 \text { and } 11 \text { compared } \\
\text { to peak at day } 5 \text { post-retrieval }\end{array}$ \\
\hline Wang et al. (2015) [25] & China & $\begin{array}{l}\text { Randomized } \\
\text { controlled trial }\end{array}$ & $4,735(281)$ & Long luteal, hCG trigger & $\begin{array}{l}\text { (1) Letrozole } 2.5 \mathrm{mg} \text { bid post-re- } \\
\text { trieval days } 1-5(n=43) \\
\text { (2) Mifepristone } 25 \mathrm{mg} \text { bid post- } \\
\text { retrieval days } 1-3(n=51) \\
\text { (3) Cetrotide } 0.25 \mathrm{mg} \text { daily post- } \\
\text { retrieval days } 1-5(n=39) \\
\text { (4) All } 3 \text { drugs }(n=28) \\
\text { (5) Controls }(n=120)\end{array}$ & $\begin{array}{l}\text { No difference in incidence of } \\
\text { moderate to severe OHSS, } \\
\text { days hospitalized, paracente- } \\
\text { sis, or duration of luteal phase }\end{array}$ \\
\hline
\end{tabular}

IVF, in vitro fertilization; $\mathrm{hCG}$, human chorionic gonadotropin; $\mathrm{GnRH}$, gonadotropin-releasing hormone; OHSS, ovarian hyperstimulation syndrome; VEGF, vascular endothelial growth factor.

a)In the case report studies, all patients were high risk; in the cohort studies, the " $n$ " indicates the number of patients evaluated in the study and the number of

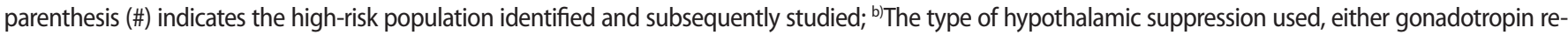
leasing hormone antagonist or, with the long luteal protocol, with a GnRH agonist.

side effects of either medications, and no urgent care visits or hospitalizations among the four patients. Bonilla-Musoles et al. [19] also published a report from Spain on six patients with OHSS treated with a much higher dose of cetrorelix $3 \mathrm{mg}$ for one or two doses. Again, the authors described a rapid resolution of symptoms, and reported no requirement for paracentesis. Finally, a paper from Iran in 2012 by Hosseini et al. [20] described 13 patients diagnosed with early OHSS that were treated with cetrorelix $0.25 \mathrm{mg}$ daily for two doses upon diagnosis. They were compared to a retrospective cohort of 14 controls similar in age and body mass index that had also been previously diagnosed with OHSS that were treated with cabergoline $0.5 \mathrm{mg}$ daily for 7 days. In the antagonist group, only one patient required hospitalization and paracentesis, while 10 of 14 patients in the cabergoline group required hospitalization and paracentesis $(7.7 \%$ vs. $71.4 \%, p=0.001)$. It is mentioned in the paper that hospitalization was determined by severity of OHSS according to criteria of ascites, hemoconcentration, hypercoagulability, shortness of breath, or other complications such as renal failure, thromboembolism, or acute respiratory distress syndrome. However, it was not clear by which specific criteria a patient was admitted or received a paracentesis, and in a non-randomized and non-blinded study such as this, the outcomes of hospitalization and paracentesis must be interpreted with caution. Interestingly, however, the authors did note that the antagonist group tended to report resolution of all symptoms of OHSS within 1 
week, while the cabergoline group tended to have resolution of symptoms after 1 week. Finally, no significant side effects of medications reported in either group [20].

In all of these studies, any potential fresh embryo transfer was cancelled due to risk of pregnancy exacerbating OHSS. However, Lainas et al. $[21,23]$ also published two papers on patients that underwent fresh embryo transfer with concurrent administration of GnRH antagonist and the birth outcomes that ensued. In the first of these two papers, published in 2009, the authors described a group of three patients diagnosed with early severe OHSS that declined cryopreservation of all embryos and consented to fresh embryo transfer along with administration of ganirelix $0.25 \mathrm{mg}$ daily for 4 days starting from post-retrieval day 6 . Of the three transfers, there was one biochemical pregnancy, one live singleton birth, and one live twin birth [21]. A follow-up larger study included 194 high-risk IVF patients, of which 22 developed early severe OHSS and were treated with ganirelix 0.25 mg starting post-retrieval day 5 for 3 days compared to 172 patients who did not develop early severe OHSS and were used as a control group. All had fresh embryo transfer, and there was no difference found between the experimental and control groups in live birth rate $(40.9 \%$ vs. $43.6 \%)$, ongoing pregnancy rate $(45.5 \%$ vs. $48.8 \%)$, duration of gestation (36.86 weeks vs. 36.88 weeks), or neonatal weight $(2,392.73 \mathrm{~g}$ vs. $2,646.56 \mathrm{~g})$, respectively [23]. Further, there were no major congenital malformations in the 14 live births in the antagonist group, and three anomalies in the 103 live births (2.9\%) in the control group. As previously seen, there were no side effects in the antagonist group, and none of the patients required hospitalization, with symptoms decreasing significantly by 6 days after initiation of antagonist.

Two larger prospective studies followed, the first by Lainas et al. [22] in 2012. In this paper, 40 of 353 total patients undergoing IVF at a single center were found to develop early OHSS by post-retrieval day 5. These 40 patients were started on ganirelix $0.25 \mathrm{mg}$ daily for 4 days and followed for 1 month. The authors noted a rapid decline $(<7$ days) in estradiol, progesterone, hematocrit, and overall symptoms with the administration of the antagonist as well as also reporting no required hospitalizations. Contrastingly, the largest study to date was performed by Wang et al. [25]. In this study, 4,735 patients undergoing IVF were followed, and 281 of these patients found to be high risk (defined as having $>20$ follicles, an estradiol level $>8,000 \mathrm{pg} / \mathrm{dL}$, ovarian volume $>10 \mathrm{~cm}^{3}$, or significant symptoms on day of retrieval) and were recruited to participate. These patients were non-randomly divided into five cohorts: 120 control patients with no treatment; 43 patients received letrozole $2.5 \mathrm{mg}$ twice daily on post-retrieval day 1 to $5 ; 51$ patients received mifepristone $25 \mathrm{mg}$ twice daily from post-retrieval day 1 to $3 ; 39$ patients received cetrorelix $0.25 \mathrm{mg}$ daily from post-retrieval day 1 to 5 ; and 28 patients received all three medications. No differences were seen among the groups in incidence of moderate to severe OHSS, days hospitalized, paracentesis, or duration of subsequent luteal phase. The only clinically significant parameter noted was a lower estradiol level in the letrozole group and the group with all three interventions compared to the groups that had no letrozole administration [25].

\section{Discussion}

The purpose of this paper was to provide a summary of the existing data regarding the use of a GnRH antagonist post-trigger to treat OHSS. Due to the significant heterogeneity of the above studies in design, drug (ganirelix vs. cetrorelix), dosing, and timing of administration, it was not possible to combine these data to perform any sort of group analysis. Therefore, at this time, no clear conclusion may be drawn as to the efficacy of this intervention. Though early observational studies appear promising, they are limited by study design, variation in treatment protocols, and low study population numbers, and the risk of publication bias. Moreover, the final and largest trial discussed argues against the benefit of antagonist use in OHSS, though this study had weaknesses including lack of randomization, lack of blinding, and no report on the number of patients requiring hospitalization (which was an outcome addressed in the majority of the prior studies).

Given the conflicting nature of the findings, it is prudent to investigate the biologic plausibility in the use of the antagonist in attenuating OHSS effects. Firstly, studies have shown a significant luteolytic effect in the ovary by decreasing endogenous $\mathrm{LH}$ secretion from the pituitary, a direct effect of the antagonist administration $[12,26,27]$. The shortening of the luteal phase via downregulation of LH activity could potentially decrease the activity in the ovary and hasten the return to baseline function $[24,26]$. Second, there is substantial evidence of $\mathrm{GnRH}$ receptors presence on the ovary, though studies investigating the function of these receptors have shown conflicting results $[24,28,29]$. Finally, and perhaps most convincing, data have demonstrated a decrease in levels of VEGF corresponding to the use of GnRH antagonists in cell culture, animal models, and even in the human $[24,30,31]$.

With only these few studies containing small sample sizes spanning over a decade and varying in treatment protocols, any conclusion on the usefulness of a GnRH antagonist to mitigate the effects of OHSS post-trigger is difficult to make. The "birds-eye" view of these data along with the basic research demonstrating the reasonable mechanisms of action suggest that more standardized, prospective trials that are better powered, randomized, and ideally blinded, would be prudent. Any future studies would do well to consider the 24 to 36 hour half-life of the HCG used in a trigger shot, as LH activity (mim- 
icked by HCG in the trigger) has been shown to be the major driver in OHSS symptomatology [32,33]. With this in mind, administration of the $\mathrm{GnRH}$ antagonist prior to post-trigger day 3 would likely have a blunted benefit, and therefore researchers may prefer to focus on therapy initiation around post trigger day 5 for maximum effect as shown in some of the above studies.

Recently, a guideline was published by the American Society for Reproductive Medicine on the prevention and treatment of moderate to severe OHSS, discussing important clinical practices including recognition of patients at risk, different stimulation protocols, and the use of medications such as cabergoline, metformin, aspirin, albumin, and calcium [10]. Missing from this otherwise extensive review on the subject is the option of using a GnRH antagonist after ovulation trigger as described above, highlighting an important gap in our knowledge of this iatrogenic pathology, and potential treatment options clinically available.

Finally, when considering any intervention in medicine, the risk/ benefit profile must be weighed. In the case of a GnRH antagonist, it is known to possess a reassuring safety profile. Coupled with the fact that it is not uncommon for a patient to have a few unused doses after administration of the ovulation trigger in an IVF cycle, would it not then be reasonable to recommend administering any remaining doses to a patient deemed to be "high risk" for OHSS? Based on the majority of the studies above, it appears that an antagonist can ameliorate symptoms, or at the least hasten recovery should symptoms occur as most patients saw resolution inside of 7 days. Summarily, it seems therefore a worthwhile consideration in the case of patients at high risk for OHSS manifesting mild to moderate symptoms several days after trigger to use any remaining doses of antagonist they may have from the IVF cycle. Until further studies either validate or refute these early findings, this should be considered a reasonable option in the armament against OHSS.

\section{Conflict of interest}

No potential conflict of interest relevant to this article was reported.

\section{Acknowledgments}

The authors would like to acknowledge Mary Peavey, MD for her review and scientific advice with this manuscript.

\section{References}

1. Practice Committee of American Society for Reproductive Medicine. Ovarian hyperstimulation syndrome. Fertil Steril 2008;90(5 Suppl):S188-93.
2. Boothroyd C, Karia S, Andreadis N, Rombauts L, Johnson N, Chapman $\mathrm{M}$, et al. Consensus statement on prevention and detection of ovarian hyperstimulation syndrome. Aust N Z J Obstet Gynaecol 2015;55:523-34.

3. Fritz MA, Speroff L. Clinical gynecologic endocrinology and infertility. 8th ed. Philadelphia: Lippincott Williams \& Wilkins; 2011.

4. Humaidan P, Quartarolo J, Papanikolaou EG. Preventing ovarian hyperstimulation syndrome: guidance for the clinician. Fertil Steril 2010;94:389-400.

5. Bellver J, Munoz EA, Ballesteros A, Soares SR, Bosch E, Simon C, et al. Intravenous albumin does not prevent moderate-severe ovarian hyperstimulation syndrome in high-risk IVF patients: a randomized controlled study. Hum Reprod 2003;18:2283-8.

6. Gokmen O, Ugur M, Ekin M, Keles G, Turan C, Oral H. Intravenous albumin versus hydroxyethyl starch for the prevention of ovarian hyperstimulation in an in-vitro fertilization programme: a prospective randomized placebo controlled study. Eur J Obstet Gynecol Reprod Biol 2001;96:187-92.

7. Graf MA, Fischer R, Naether OG, Baukloh V, Tafel J, Nuckel M. Reduced incidence of ovarian hyperstimulation syndrome by prophylactic infusion of hydroxyaethyl starch solution in an in-vitro fertilization programme. Hum Reprod 1997;12:2599-602.

8. Westphal M, James MF, Kozek-Langenecker S, Stocker R, Guidet B, Van Aken H. Hydroxyethyl starches: different products--different effects. Anesthesiology 2009;111:187-202.

9. Abbara A, Jayasena CN, Christopoulos G, Narayanaswamy S, IzziEngbeaya C, Nijher GM, et al. Efficacy of kisspeptin-54 to trigger oocyte maturation in women at high risk of ovarian hyperstimulation syndrome (OHSS) during in vitro fertilization (IVF) therapy. J Clin Endocrinol Metab 2015;100:3322-31.

10. Practice Committee of the American Society for Reproductive Medicine. Prevention and treatment of moderate and severe ovarian hyperstimulation syndrome: a guideline. Fertil Steril 2016;106:1634-47.

11. Hill MJ, Chason RJ, Payson MD, Segars JH, Csokmay JM. GnRH antagonist rescue in high responders at risk for OHSS results in excellent assisted reproduction outcomes. Reprod Biomed Online 2012;25:284-91.

12. Gilliam ML. Gonadotrophin-releasing hormone antagonists for assisted reproductive technology. Obstet Gynecol 2011;118:7067.

13. Youssef MA, Van der Veen F, Al-Inany HG, Mochtar MH, Griesinger G, Nagi Mohesen M, et al. Gonadotropin-releasing hormone agonist versus HCG for oocyte triggering in antagonist-assisted reproductive technology. Cochrane Database Syst Rev 2014; (10):CD008046.

14. Fatemi HM, Garcia-Velasco J. Avoiding ovarian hyperstimulation 
syndrome with the use of gonadotropin-releasing hormone agonist trigger. Fertil Steril 2015;103:870-3.

15. de Jong D, Macklon NS, Mannaerts BM, Coelingh Bennink HJ, Fauser BC. High dose gonadotrophin-releasing hormone antagonist (ganirelix) may prevent ovarian hyperstimulation syndrome caused by ovarian stimulation for in-vitro fertilization. Hum Reprod 1998;13:573-5.

16. Lainas TG, Sfontouris IA, Zorzovilis IZ, Petsas GK, Lainas GT, Kolibianakis EM. Management of severe early ovarian hyperstimulation syndrome by re-initiation of GnRH antagonist. Reprod Biomed Online 2007;15:408-12.

17. Lainas TG, Sfontouris IA, Zorzovilis IZ, Petsas GK, Lainas GT, lliadis GS, et al. Management of severe OHSS using GnRH antagonist and blastocyst cryopreservation in PCOS patients treated with long protocol. Reprod Biomed Online 2009;18:15-20.

18. Rollene NL, Amols MH, Hudson SB, Coddington CC. Treatment of ovarian hyperstimulation syndrome using a dopamine agonist and gonadotropin releasing hormone antagonist: a case series. Fertil Steril 2009;92:1169.e15-7.

19. Bonilla-Musoles FM, Raga F, Castillo JC, Sanz M, Dolz M, Osborne $\mathrm{N}$. High doses of $\mathrm{GnRH}$ antagonists are efficient in the management of severe ovarian hyperstimulation syndrome. Clin Exp Obstet Gynecol 2009;36:78-81.

20. Hosseini MA, Mahdavi A, Aleyasin A, Safdarian L, Bahmaee F. Treatment of ovarian hyperstimulation syndrome using gonadotropin releasing hormone antagonist: a pilot study. Gynecol Endocrinol 2012;28:853-5.

21. Lainas TG, Sfontouris IA, Zorzovilis IZ, Petsas GK, Lainas GT, Alexopoulou $\mathrm{E}$, et al. Live births after management of severe OHSS by $\mathrm{GnRH}$ antagonist administration in the luteal phase. Reprod Biomed Online 2009;19:789-95.

22. Lainas GT, Kolibianakis EM, Sfontouris IA, Zorzovilis IZ, Petsas GK, Tarlatzi TB, et al. Outpatient management of severe early OHSS by administration of $\mathrm{GnRH}$ antagonist in the luteal phase: an observational cohort study. Reprod Biol Endocrinol 2012;10:69.

23. Lainas GT, Kolibianakis EM, Sfontouris IA, Zorzovilis IZ, Petsas GK, Lainas TG, et al. Pregnancy and neonatal outcomes following luteal GnRH antagonist administration in patients with severe early OHSS. Hum Reprod 2013;28:1929-42.

24. Lainas GT, Kolibianakis EM, Sfontouris IA, Zorzovilis IZ, Petsas GK,
Lainas TG, et al. Serum vascular endothelial growth factor levels following luteal gonadotrophin-releasing hormone antagonist administration in women with severe early ovarian hyperstimulation syndrome. BJOG 2014;121:848-55.

25. Wang YQ, Luo J, Xu WM, Xie QZ, Yan WJ, Wu GX, et al. Can steroidal ovarian suppression during the luteal phase after oocyte retrieval reduce the risk of severe OHSS? J Ovarian Res 2015;8:63.

26. Mais V, Kazer RR, Cetel NS, Rivier J, Vale W, Yen SS. The dependency of folliculogenesis and corpus luteum function on pulsatile gonadotropin secretion in cycling women using a gonadotropin-releasing hormone antagonist as a probe. J Clin Endocrinol Metab 1986;62:1250-5.

27. Nelson LR, Fujimoto VY, Jaffe RB, Monroe SE. Suppression of follicular phase pituitary-gonadal function by a potent new gonadotropin-releasing hormone antagonist with reduced histamine-releasing properties (ganirelix). Fertil Steril 1995;63:963-9.

28. Ortmann O, Weiss JM, Diedrich K. Embryo implantation and $\mathrm{GnRH}$ antagonists: ovarian actions of $\mathrm{GnRH}$ antagonists. Hum Reprod 2001;16:608-11.

29. Peng C, Fan NC, Ligier M, Vaananen J, Leung PC. Expression and regulation of gonadotropin-releasing hormone $(\mathrm{GnRH})$ and $\mathrm{GnRH}$ receptor messenger ribonucleic acids in human granulosa-luteal cells. Endocrinology 1994;135:1740-6.

30. Asimakopoulos B, Nikolettos N, Nehls B, Diedrich K, Al-Hasani S, Metzen $\mathrm{E}$. Gonadotropin-releasing hormone antagonists do not influence the secretion of steroid hormones but affect the secretion of vascular endothelial growth factor from human granulosa luteinized cell cultures. Fertil Steril 2006;86:636-41.

31. Tong XM, Zhang SY, Song T, Xu WH, Lin XN, Shu J, et al. Effects of gonadotropin-releasing hormone antagonists on the expression of vascular endothelial growth factor and its receptors in a rat model of ovarian hyperstimulation syndrome. Chin Med J (Engl) 2008;121:2434-9.

32. Navot D, Bergh PA, Laufer N. Ovarian hyperstimulation syndrome in novel reproductive technologies: prevention and treatment. Fertil Steril 1992;58:249-61.

33. O'Neill KE, Senapati S, Maina I, Gracia C, Dokras A. GnRH agonist with low-dose hCG (dual trigger) is associated with higher risk of severe ovarian hyperstimulation syndrome compared to $\mathrm{GnRH}$ agonist alone. J Assist Reprod Genet 2016;33:1175-84. 